LETTERS TO THE EDITOR.

[7'he Editor does not hold himself responsible for opinions ex. pressed by his correspondents. Neither can he undertake to retum, or to correspond with the writers of, rejected manuscrifts intended for this or any other part of NATURE. No notice is taken of anonymous communications.]

\section{The Fullerian Professorship of Physiology at the Royal Institution.}

I AM writing in the assurance that my letter will or will not appear in your columns, according as you shall have judged whether or no it deals with public matter. And this again depends upon the degree in which the Royal Institution of Great Britain is regarded as fulfilling a public function.

Briefly, the facts are these :-

I hold the "Fullerian Professorship of Physiology and Comparative Anatomy" at the Royal Institution. I am surprised and disappointed to find that the duties of that post are regarded in a very flimsy light, and that no provision can be made, either in the Institution itself or in the arljoining Davy-Faraday Laboratory towards their more adequate performance. The obvious fact that the lecture-room rests upon the laboratory, acted upon with such admirable effect in the case of physics and chemistry, is altogether ignored in the case of physiology, with the result that the instruction that can be offered to the public in this latter subject is deficient or inferior, and-in the bad sense of these words-popular and literary. The very excellence of the lecturetheatre, together with the absence of any work-room, diverts the activity of the chair into other than its proper channels.

The Royal Institution of Great Britain, although it arose by private enterprise, has now for many years occupied the place of a public organ of natural knowledge, and its title expresses its de facto relation to the educated public, who look to the Royal Institution for the best information that can be given in the various subjects there dealt with.

It is a matter for regret-indeed in the present state of ignorance of physiology, which by many otherwise well-informed persons is supposed to be synonymous with vivisection-it is an actual misfortune, that the Fullerian Professors of Physiology are not enabled to give to the Institution the best work of which they may be capable. To profess "physiology" of an inferior character, under the auspices of the Royal Institution of Great Britain, is misleading and injurious to the interests of science.

I have felt some hesitation before requesting you to publish this letter, but can see no other means of testing the correctness of my opinion as to what is due to the public at the Royal Institution of Great Britain by the channel of its Fullerian Professorship of Physiology. Augusters D. Watler.

July 5 .

\section{Streaming Movements of the Protoplasm in Pollen of} Flowers.

IT may, perhaps, not be generally known that pollen of flowers affords a convenient example of the circulation of proto. plasm. If pollen from a fox-glove be placed in a solution of sugar at ordinary temperature in a drop-slide, the grains sprout within twenty minutes, and grow during several hours at an average rate of $\mathrm{I} / \mathrm{IO}$ millimetre per hour. The granules of protoplasm move in opposite streams side by side, turning at the lower end of the tube and inside the grain ; the rate of motion may be calculated at I millimetre in one and a half to two minutes. The rapidity and duration of the streaming movement vary in different species; in the pollen of the fox-glove it seldom continues longer than five or six hours, but in that of the hee orchis it may be still observed on the third day, after the tubes have ceased to grow. Protoplasm which has been set free by the bursting of tubes or grains, continues to show signs of life for a longer period. The granular character of the protoplasm is less distinct in some species than in uthers, but with a sufficiently high power $-\mathrm{I} / 8$ - a visible motion of the contents of pollen tubes appears to be common.

July I 3 .

Sensitiveness of the Retina to X-Rays.

WHile trying a few days ago to detect the position of a coin which a child had swallowed, I found that the retina is affected by the X-rays. I have since learnt that this observation is not new, but my method of work may be of interest. For the purpose of the coin experiment the tube of the usual Jackson type was placed immediately under a table of $\mathrm{x}$-inch deal in a dark room; on bringing my eye close to that part of the table where a phosphorescent screen showed the most intense radiation, after I had been in the dark for at least ten minutes, I could perceive a faint illumination of the retina, and on moving small metal objects to and fro immediately in front of the eye, I could see their shadows on the retina appearing to move always in the opfosite direction. On moving the eye further away from the object the shadow enlarged. It is possible to make out the shape of small letters about $\frac{1}{4}$-inch long cut out in the middle of a sheet of lead, if they are placed close to the eye. It makes very little difference whether the eyelid is open or shut. The front of the eyeball in my experiment was about 4 inches from the platinum radiating plate.

The condition for success is that the observer should be in the dark for some time-not less than ten minutes, and in some cases twenty minutes. A person who has recently been in full daylight appears to require a longer time in the dark before the sensitive condition is developed.

Mason College, July I.

Guy Oliver Harrison.

\section{Distant Stars.}

IN the interesting extract of Prof. Newcomb's address at the Flower Observatory, University of Pennsylvania, given in NATURE, p. 139, on the distance of the stars, he says :-

"Evidence is gradually accumulating which points to the probability that the successive orders of smaller and smaller stars, which our continually increasing telescopic power brings into view, are not situated at greater and greater distances, but that we actually see the boundary of the universe," $\&$ c.

It would be extremely interesting if some of the reasons for this theory were given; it seems so startling to imagine that after all we are practically the "hub of the universe," or very nearly so; and so opposed to the idea that what our most powerful telescopes can show, may possibly only be in proportion to the whole universe as one drop of water to the Atlantic Ocean.

\section{ALbERT COLLISON.}

\section{Sound of Distant Firing.}

I SEE a correspondent reports hearing the saluting at the Portsmouth Naval Review at Chelsea. It was distinctly audible here, loud enough to be heard at some distance further, though the wind was E.S.E., a fresh breeze, and therefore unfavourable for helping sound. Also there were no clouds-in sight, anyhow-which might aid in reflecting the sound-waves. The reports began a few minutes after 2 p.m., and continued at intervals up to nearly three o'clock, at which time I ceased listening for them. I make the air-line distance just sixty statute miles.

I may add that, when walking on Wimbledon Common, I frequenily hear loud detonation, which I put down to Shoe. buryness, as I do not know of any other place in that direction at which heavy firing takes place. The distance would be about fifty, miles, but across London, which one would think might interfere with sound-transmission.

Wimbledon, July I 2.

\section{Blackbird's Nest appropriated by a Wagtail.}

THE double bird's nest I send you was found some time agc in a stack of hop-poles when they were taken down for use. The lower nest is clearly a blacktird's, and in it, below the lining, were two blackbird's eggs when found. The upper nest (or lining ?) is, I am informed, that of a pied-wagtail, with four eggs, and also the egg of a cuckoo. It is suggested the blackbird was disturbed (by a cuckoo?), and a wagtail, assuming the nest, completed it in its own fashion, the cuckoo therein laying its egg. (The same cuckoo which had disturbed the blackbird?)

The double nest was found by Mr. Pattenden, a farmer here, and seen by his wife and son in situ. I have sent you a letter written by the son, and stating how the nest was found. I do not doubt the story is true.

Burwash, Sussex, July 7 .

NO. 1446 , VOL. 56] 